\section{No bias behind pollinator research}

We disagree with Ian Boyd's implication that bias may have influenced the commissioning and publication of research on pollinator declines (Nature 501, 159-160; 2013).

Our paper on falls in European bee-species richness (J. C. Biesmeijer et al. Science 313, 351-354; 2006), along with others on honeybee colony collapse and bumblebee declines, prompted widespread public concern. Subsequent decisions in continental Europe and the United Kingdom to commission further research in this area therefore seemed sensible and proportionate.

These calls for research used "pollinator declines" as a convenient shorthand, not to steer the work. This is borne out by results from the studies funded, including our own, indicating that past declines in some pollinator groups may have recently slowed or even partially reversed (L. G. Carvalheiro et al. Ecol. Lett. 16, 870-878; 2013).

Publication bias undoubtedly occurs, but it can be identified only by reviewing whole fields, not individual papers. This should be addressed as part of a systematic review when policy issues arise, as carried out by the UK's Parliamentary Office of Science and Technology or by independent research teams.

We agree that there are uncertainties in our conclusions, as Boyd suggests; indeed, our papers list strong caveats pertaining to our data sets and methodology, which were largely ignored by the media.

A national pollinatormonitoring programme, recommended recently in a parliamentary report, would provide much more robust estimates of pollinator trends in future.

William E. Kunin* University of Leeds, UK.

w.e.kunin@leeds.ac.uk
${ }^{\star}$ On behalf of 5 co-signatories (see go.nature.com/setpu6 for full list).

\section{Genetic engineering in conservation}

Species bearing genetically engineered adaptive variants that are intended to save them from extinction might differ in important respects from the original species designated for protection - with unpredictable ecological consequences (see M. A. Thomas et al. Nature 501, 485-486; 2013).

Introducing adaptive variants by genetic engineering might work for some long-lived plants in which disease resistance is primarily due to a single gene (J. M. Adams et al. Conserv. Biol. 16, 874-879; 2002), and for economically important traits in agricultural crops grown in controlled environments. In wild endangered species, however, identifying 'missing' adaptive single-gene variants and increasing their frequency without causing negative side effects is almost certain to prove impossible.

Genetically based inferior fitness in endangered populations — including in the Florida panthers and Swedish vipers cited by Thomas and his colleagues has been traced to an increased frequency of detrimental alleles from inbreeding or a loss of genetic variation, and not to a lack of adaptive variants.

Improving connectivity with outside populations would rescue the fitness of such endangered populations by introducing greater genetic variation, non-detrimental variants, and adaptive alleles that have already been well tested by evolution.

Philip W. Hedrick Arizona State University, Tempe, USA.

philip.hedrick@asu.edu

Fred W. Allendorf University of Montana, Missoula, USA.

Robin S. Waples National

Marine Fisheries Service, Seattle, Washington, USA.

\section{Safeguard species in warming flatlands}

To protect the biodiversity of

flatlands against the effects of climate change (M. Tingley et al. Nature 500, 271-272; 2013), we need strategies to buy time for species to adapt to warmer environments or to move to cooler ones. This will mean adding more protected areas in cool regions and improving connectivity between protected sites.

One way to increase resilience among resident communities would be to reduce the intensity of summer grazing on flatlands. Shade from tall, dense swards helps to cool the soil by up to $5{ }^{\circ} \mathrm{C}$ (J. A. Thomas et al. Science $325,80-83 ; 2009)$, an effect that is enhanced as the land becomes more uneven (J. Settele and E. Kühn Science 325, 41-42; 2009).

Conservation measures in existing protected sites, as in Europe's Natura 2000 programme (see go.nature.com/ ykf7vt), remain important but may prove inadequate on their own and will need to be adapted and revivified as the climate warms.

Josef Settele, Ingolf Kühn Helmholtz Centre for

Environmental Research, Halle, Germany.

josef.settele@ufz.de

Jeremy A. Thomas University of Oxford, UK.

\section{Metaphors advance scientific research}

As a former collaborator in Eleonore Pauwels' research on the misuse of metaphors by synthetic biologists, I agree with many of her points but find her perspective too restrictive (Nature 500, 523-524; 2013). In my view, the use of analogies, concepts and metaphors is crucial for advancing scientific research.

Pauwels tends to merge metaphors with analogies and theoretical concepts. Her examples of oscillators, switches and logic gates, which have a precise meaning in engineering, are better viewed as the analogical transfer of a scientific concept (see also B. Calcott Nature 502, 170; 2013). To treat them as though they were on a par with expressions such as 'selfish gene,' 'software of life' or 'household of nature' does not capture the ways in which they are used in scientific practice.

Metaphors and analogies have long driven cross-disciplinary exchange. For example, the early mathematization of biology and economics in the nineteenth and twentieth centuries was largely built on analogies with physics. Analogies and metaphors have also contributed substantially to ideas developed in cognitive science and in the philosophy and history of science (reviewed in J. Maienschein et al. Isis 99, 341-349; 2008).

Andrea Loettgers University of Geneva, Switzerland. andrea.loettgers@unige.ch

\section{Keep PubMed running at all costs}

With more than 23 million citations to date from MEDLINE, life-science journals and online books, the giant National Institutes of Health database PubMed is arguably the most valuable tool available to biomedical scientists. Its vulnerability has been highlighted by this month's partial US government shutdown, with only minimal updates and maintenance to PubMed possible.

To avoid lapsing into another dark age of research, the ongoing maintenance of PubMed must be guaranteed. We urge the scientific community to push for PubMed to be entirely supported and commissioned by an international forum. Alex W. Hewitt, David A. Mackey Lions Eye Institute, Perth, Australia. hewitt.alex@gmail.com 